\section{Finding Room for Success}

A s I write this, I am at the annual meeting of the American Association for Cancer Research, listening to the latest developments in immuno-oncology, including chimeric antigen receptor (CAR) T cells. There is already one CAR T-cell product approved for lymphoid malignancies. This form of cell therapy is technically challenging, quite costly, and sometimes very toxic, but it can have transformative effects, especially in children. Personally, I think it's only a matter of time before researchers are able to make this work in other hematologic malignancies and in solid tumors. We must figure out how to make these cells persist, penetrate, and stay active at the tumor interface. But we'll get it done.

What concerns me is how we will integrate all this into our existing infrastructure for cancer care. After all, this therapy doesn't replace what we do; it adds to it!

It's already been challenging to set this treatment up for the 2 existing indications. Thank goodness the breakthrough came in hematologic malignancies! Our stem cell transplant teams have all the right stuff. They are already used to cell processing and caring for very sick patients. But transplantation is not going away, and we only have so many beds and trained personnel. If CAR T-cell therapy takes off, how will we ramp up to care for everyone?

Fortunately, some of the infrastructure is being handled by the manufacturers themselves. Obviously, they need to do the product engineering, so they are building large-capacity units. However, the cells still need to be collected on-site before shipping, and then retrieved and stored properly on-site before administration, so pheresis units and cell processing capacity will still need to increase.

And where will we put all of these patients and who will treat them? Because of cytokine release syndrome, these patients can get very sick. They do need hospitalization, at least for now. We can't expect our colleagues on transplant teams to absorb a growing business involving patients with solid tumors. My guess is that, just as we did when bone marrow transplantation came on the scene, we will develop specialized units and teams to do this well. Our hospitals will need to find space for this activity just as they have always made room for other effective specialized forms of care. I hope they are thinking hard about how to get this done.

I haven't even begun to sort out the business details. One interesting aspect of tisagenlecleucel (Kymriah, Novartis), approved for B-cell acute lymphoblastic leukemia, is that the product itself is free. . . unless it works. Then it costs $\$ 475,000$. No, I didn't accidentally put in extra zeros; it really costs that much. But, at least for kids, studies have shown that it is cost-effective.

Of course, there's an additional charge for the hospitalization. Will the facility reimbursement be enough to support expansion of beds? I don't know, but I hope so. I also hope we can find ways to make this less toxic, allowing us to manage it in the outpatient setting.

I think cell therapy is here to stay. We have always managed to make room for a good thing, but we have a lot to figure out. Let's roll up our sleeves and get busy! We've got work to do! JNCCN@nccn.org or log into www.editorialmanager.com/JNCCN.

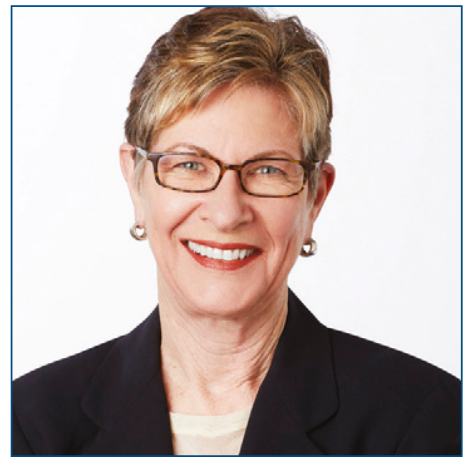

MARGARET TEMPERO, MD

Margaret Tempero, MD, is a Professor of Medicine and Director of the UCSF Pancreas Center and editor-in-chief of JNCCN. Her research career has focused on pancreatic ductal adenocarcinoma, especially in the area of investigational therapeutics. Dr. Tempero has served on the ASCO Board of Directors and as ASCO President. She currently serves on the ASCO Conquer Cancer Foundation Board. She codirected the AACR/ASCO Methods in Clinical Cancer Research and taught this course and similar courses in Europe and Australia. She was founding Chair of the $\mathrm{NCl}$ Clinical Oncology Study Section and served as a member and Chair of the $\mathrm{NCl}$ Board of Scientific Counselors Subcommittee A. She is a member of the Scientific Steering Committee and Chair of the Clinical and Translational Study Section for the Cancer Prevention \& Research Institute of Texas. She is or has been on the Scientific Advisory Boards of the Lustgarten Foundation, the Pancreatic Cancer Action Network, the $\checkmark$ Foundation, The Alberta Canada Cancer Board, and the EORTC. She served as a member of the Oncology Drug Advisory Committee for the FDA. She has served as Deputy Director and Interim Director for the UNMC Eppley Cancer Center. She is Chief Emeritus of the Division of Medical Oncology at UCSF and served as the founding Deputy Director and Director of Research Programs at the UCSF Helen Diller Family Comprehensive Cancer Center.

doi: $10.6004 /$ jnccn.2019.0025

The ideas and viewpoints expressed in this editorial are those of the author and do not necessarily represent any policy, position, or program of NCCN. 